\title{
Cloning and sequencing of the gene for a putatively nematode-toxic crystal protein, Cry21Ba1, from Bacillus thuringiensis serovar roskildiensis
}

\author{
Kenji Sato ${ }^{1,2}$ and Shin-ichiro Asano ${ }^{3}$
}

\begin{abstract}
We have cloned and sequenced a gene encoding a novel crystal (Cry) protein, Cry21Ba1, from Bacillus thuringiensis serovar roskildiensis. The gene, cry21Ba1, was amplified by polymerase chain reaction using template (alkaline-cell lysate or plasmid DNA fraction of the Bacillus) and primers (pairs of oligomeric DNAs designed from the conserved amino-acid sequence blocks of Cry5-Cry12-Cry13-Cry14-Cry21-type Cry proteins), and was cloned followed by sequencing. The gene, cry21Ba1, should be functional, because it has putative promoter sequences upstream of the initiation codon and an inverted repeat downstream of the stop codon. The open reading frame (ORF) of cry21Ba1 is a 3,858-bp DNA encoding Cry21Ba1 consisting of 1,286 amino acids. The nucleotide sequence of the $c r y 21 \mathrm{Ba} 1 \mathrm{ORF}$ is $75 \%$ identical with that of the $\mathrm{cry} 21 \mathrm{Aa1}$ (the gene for a known nematode-toxic Cry protein, Cry21Aa1) ORF. The amino acid sequence of Cry21Ba1 is $67 \%$ identical with that of Cry21Aa1. High amino-acid-sequence similarity between these Cry proteins indicates that Cry21Ba1 is putatively nematode-toxic. Jpn. J. Nematol. 34 (2) , 79-88 (2004).

Key words: $B t$, Cry protein, $c r y$ gene, cry21Ba1, plant-pathogenic nematode.
\end{abstract}

\section{INTRODUCTION}

Crystal (Cry) proteins produced by Bacillus thuringiensis $(B t)$ are the most widely used biological insecticides, because they are insecticidal but practically nontoxic to vertebrates (Schnepf et al., 1998). At present, some cry genes are successfully used to introduce insect-resistance into plants (Schnepf et al., 1998). If Cry proteins potently toxic to plant-pathogenic nematodes are found from $B t$ strains, the cry genes may be used to introduce nematode-resistance into plants (Atkinson et al., 2003), because many species of

\footnotetext{
${ }^{1}$ Laboratory of Applied Entomology, Department of AgroBioscience, Faculty of Agriculture, Iwate University, Morioka 020-8550, Japan.

${ }^{2}$ Corresponding author, e-mail: ucmgplk@mail.goo.ne.jp

${ }^{3}$ Laboratory of Applied Molecular Entomology, Division of Applied Bioscience, Graduate School of Agriculture, Hokkaido University, Sapporo 060-8589, Japan.
}

agronomically important plant-pathogenic nematodes parasitize plant tissue (Sasser and Freckman, 1987).

However, at present, studies on the nematode-toxic Cry proteins are not so general, and only four Cry proteins (i.e., mutually amino-acid sequence-similar Cry5B, Cry14A, and Cry21A (Marroquin et al., 2000; Griffits et al., 2001; Wei et al., 2003), and another Cry protein, Cry6A (Wei et al., 2003)) have been proved to be toxic to certain free-living and rat-intestinal nematodes. Furthermore, information on the cloning and sequencing of the nematode-toxic cry genes is scarce, perhaps because all these cry genes reported until now are patented materials, i.e., cry5Aa1 (Sick et al., 1994), cry5Ab1 and cry12Aa1 (Narva et al., 1991), cry5Ba1 (Payne and Michaels, 1995), cry13Aa1 (Schnepf et al., 1992), cry14Aa1 (Payne and Narva, 1994), 
cry21Aa1 (Payne et al., 1996), cry21Aa2 (Feitelson, 1997), cry6Aa1 (Narva et al., 1993) and cry6Ba1 (Narva et al., 1991). In this situation, enrichment of such information may contribute to the advance of studies on the nematode-toxic Cry proteins, and this advance may lead to finding $B t$ strains carrying new cry genes potently toxic to plant-pathogenic nematodes.

In this paper, we will present the information on the cloning and sequencing of a gene encoding a novel Cry protein, Cry21Ba1, from Bacillus thuringiensis serovar roskildiensis.

\section{MATERIALS AND METHODS}

Bacterial strains:

Sixty-nine Bacillus thuringiensis $(B t)$ strains of the IEBC (International Entomopathogenic Bacillus Centre at Institut Pasteur, Paris, France) Collection (Lecadet et al., 1999) were shake-cultured at $30^{\circ} \mathrm{C}$ for $24-48 \mathrm{~h}$ in Bacto Tryptose Phosphate Broth (Becton, Dickinson and Company, Franklin Lakes, New Jersey, USA).

Template preparation for PCR:

Alkaline-cell lysate or plasmid DNA fraction was prepared from $B t$ cells, and was used as the template for polymerase chain reaction (PCR) amplification. Alkaline-cell lysate was prepared by the method of O'Reilly et al. (1992) with some modifications, as follows. Five $\mu \mathrm{l}$ of $B t$ culture was added to $100 \mu$ l of ice-cold $0.1-\mathrm{N} \mathrm{NaOH}$ in a microtube and left on ice for $5 \mathrm{~min}$. The cell lysate obtained was neutralized by adding $20 \mu \mathrm{l}$ of 1-M ammonium acetate, and was immediately used as the template for PCR. Plasmid DNA fraction was prepared from the culture of $B$. thuringiensis serovar roskildiensis with QIAprep Spin Miniprep Kit (QIAGEN GmbH, Hilden, Germany) by the manufacturer's method with some modifications. Briefly the $B t$ cells were collected by low-speed centrifugation $(5,000 \times \mathrm{g}$ for 2 to $3 \mathrm{~min}$ ) from $4 \mathrm{ml}$ of the culture, and were suspended in $225 \mu \mathrm{l}$ of RNase-A-supplemented
Buffer P1 (QIAGEN). The cell suspension obtained was added with $25 \mu$ l of lysozyme solution $(10 \mathrm{mg} / \mathrm{ml}$ in $10-\mathrm{mM}$ Tris- $\mathrm{HCl}, \mathrm{pH} 8.0)$, and was incubated at $37^{\circ} \mathrm{C}$ for $0.5-1.0 \mathrm{~h}$ to lyse the cells. The plasmid DNA fraction prepared from the lysate was stored at $-20^{\circ} \mathrm{C}$ until used for $\mathrm{PCR}$ or the southern hybridization analysis. PCR:

Primers (oligomeric DNAs showed in Table 1) for PCR were designed from the conserved amino-acid sequence blocks of two distinct Cry protein groups (i.e., Cry1 group and Cry5-Cry12Cry13-Cry14-Cry21 group; Schnepf et al., 1998) with a primer-analysis software, OLIGO 4.0 Macintosh (Molecular Biology Insights Inc., Cascade, Colorado, USA). PCR was performed using Ex Taq polymerase (Takara Bio Inc., Otsu, Shiga, Japan), alkaline-cell lysate or plasmid-DNA fraction as template, and an appropriate pair of forward and reverse primers, with the stepdown program (Hecker and Roux, 1996) as follows: the denaturation time and temperature was $10 \mathrm{sec}$ at $98^{\circ} \mathrm{C}$, the annealing time and temperature was $30 \mathrm{sec}$ at $72-36^{\circ} \mathrm{C}$ (decreased by $4^{\circ} \mathrm{C}$ intervals), the extension time and temperature was $2 \mathrm{~min}$ (for the amplification of $<1 \mathrm{~kb}$ ) or $5 \mathrm{~min}$ (for the amplification of $\geq 1 \mathrm{~kb}$ ) at $72^{\circ} \mathrm{C}$, each cycle with the identical annealing temperature was repeated 3 times, and the total cycle number was 30 .

Cloning and sequencing of PCR products:

PCR products were cloned using a cloning vector pCR-TOPO (Invitrogen Corporation, Carlsbad, California, USA). Subsequently, the PCR products were sequenced by the dye-terminator method (Lee et al., 1992) with a capillarybased sequencer ABI 310 (Applied Biosystems, Foster City, California, USA) or a polyacrylamide gel-based sequencer ABI 377 (Applied Biosystems) using template (pCR-TOPO vector containing the PCR product), primer (M13 Forward Primer, 5'-GTAAAACGACGGCCAG, or 


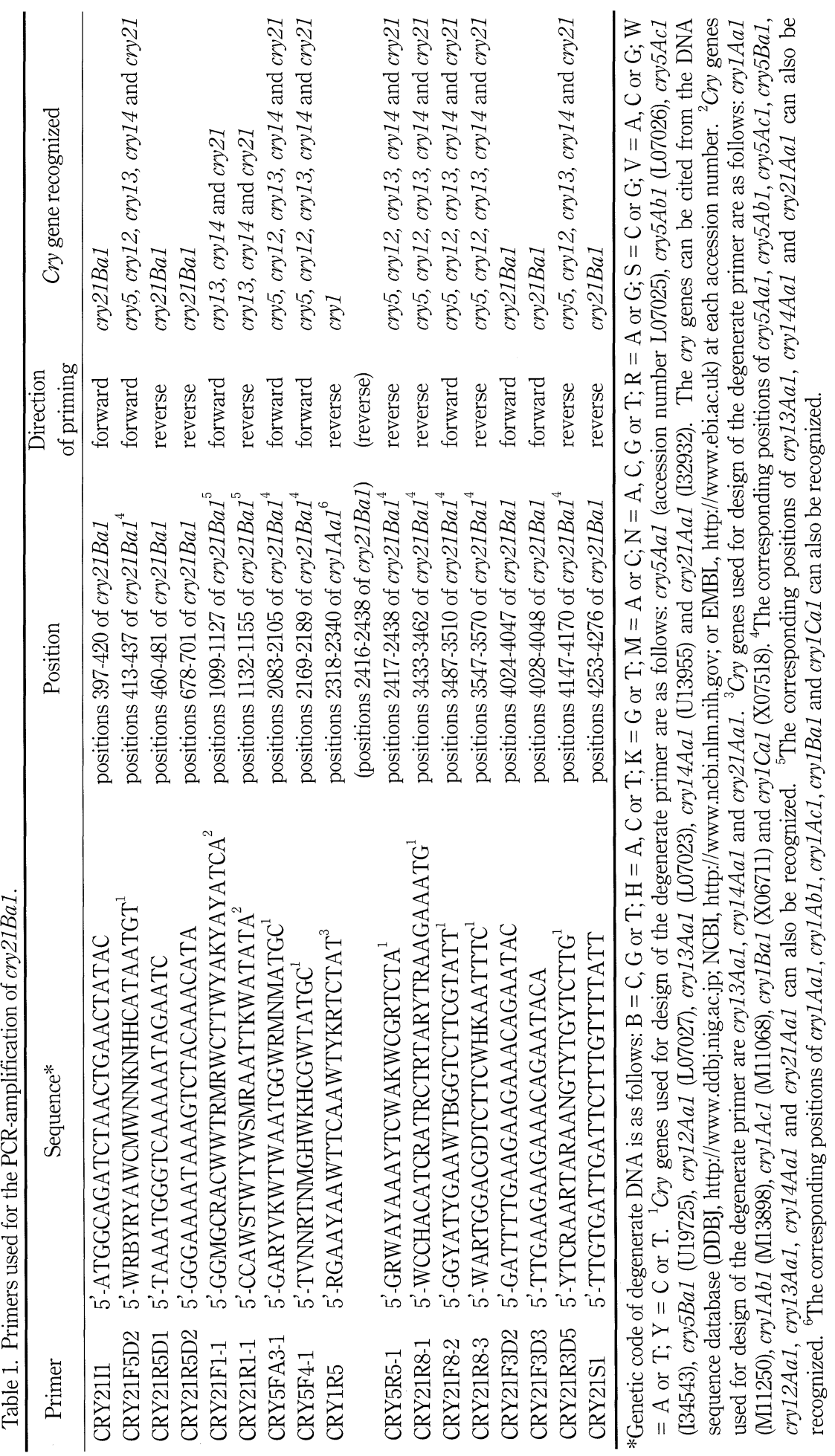


M13 Reverse Primer, 5’-CAGGAAACAGCTATGAC; Invitrogen) and BigDye Terminator Cycle v2.0 Sequencing Ready Reaction Kit (Applied Biosystems). At least five clones of each PCR product were subjected to sequencing.

Southern hybridization analysis:

Plasmid DNA fraction of B. thuringiensis serovar roskildiensis was digested with each of thirteen restriction enzymes: $A p a \mathrm{I}, B g l \mathrm{II}, E c o R \mathrm{I}$, KpnI, NotI, PstI, SacI, SalI, SmaI, SpeI, SphI, $X b a \mathrm{I}$ and XhoI. The restriction-enzyme fragments were separated by electrophoresis with a $1.0 \%$ agarose gel, and then vacuum-transferred to a positive-charged nylon membrane Hybond$\mathrm{N}+$ (Amersham Biosciences Corp., Piscataway, New Jersey, USA) immersed in $20 \times$ SSC (3-M $\mathrm{NaCl}, 0.3-\mathrm{M}$ sodium citrate, $\mathrm{pH}$ 7.0). The transferred restriction-enzyme fragments were fixed to the membrane by UV irradiation. Two probes were amplified and used as follows: (1) a 2,364-bp DNA (positions 1099-3462 of cry21Ba1; Figs 1 and 2) was PCR-amplified with primers, CRY21F1-1 and CRY21R8-1, from the plasmid DNA fraction, and was used for the detection of the 5' flanking region of cry21Ba1; (2) a 684-bp DNA (positions 3487-4170 of cry21Ba1; Figs 1 and 2) was PCR-amplified with primers, CRY21F8-2 and CRY21R3D5, from the plasmid DNA fraction, and was used for the detection of the 3 ' flanking region of cry21Ba1. Labeling of the probes with horseradish peroxidase and subsequent detection of the DNA fragments which hybridized with either of the labeled probes were performed with ECL Direct Nucleic Acid Labeling and Detection System (Amersham Biosciences) according to the manufacturer's instructions. For the southern hybridization analysis of intact plasmid DNAs, the plasmid DNA fraction was electrophoresed with a $1.0 \%$ agarose gel, and subsequently, the separated plasmid DNAs were treated as described above. Sequencing of the flanking regions of cry $21 \mathrm{Ba1}$ :
EcoRI $(3.5 \mathrm{~kb})$ and $X b a \mathrm{I}(5.5 \mathrm{~kb})$ fragments were excised from the plasmid DNA fraction of B. thuringiensis serovar roskildiensis, and were purified by agarose-gel electrophoresis with a $0.9 \%$ low-melting point agarose (SeaPlaque GTG Agarose; Cambrex Corporation, East Rutherford, New Jersey, USA) gel. The purified $E c o$ RI and $X b a \mathrm{I}$ fragments were blunted with DNA Blunting Kit (Takara Bio), and were cloned with a cloning vector pCR-Blunt (Invitrogen). The 5' flanking region was sequenced with template (the plasmid-DNA fraction or pCR-Blunt vector containing the 3.5-kb EcoRI fragment) and primer (CRY21R5D1, CRY21R5D2, M13 Forward Primer [Invitrogen] or M13 Reverse Primer [Invitrogen]). The 3' flanking region was sequenced with template (the plasmid-DNA fraction or pCR-Blunt vector containing the $5.5-\mathrm{kb}$ $X b a \mathrm{I}$ fragment) and primer (CRY21F3D2 or CRY21F3D3). The sequencing was performed by the dye-terminator method as described above.

Sequence alignment:

Alignment of cry21Ba1 with cry21Aa1 for the nucleotide sequence or the deduced aminoacid sequence was performed with a gene-information analysis software, GENETYX-MAC 8.0 (GENETYX Corporation, Tokyo, Japan).

\section{RESULTS}

Cloning and sequencing of $\mathrm{PCR}$ products:

Initially, we tried to amplify a 300-400-bp DNA corresponding to the amino acid sequence between the alternate conserved amino-acid sequence block 3 and the conserved amino-acid sequence block 5 of Cry5-Cry12-Cry13-Cry14Cry21-type Cry protein (Table 1 and Fig. 1). Consequently, a 356-bp DNA was PCR-amplified from $B$. thuringiensis serovar roskildiensis by the following two steps: (1) the first PCR was performed using template (the alkaline-cell lysate) and primers (CRY5FA3-1 and CRY5R5-1; Fig. 2); 
(2) the second PCR was performed using template (reaction mixture of the first PCR after it had been performed) and primers (CRY5FA3-1 and CRY1R5 instead of CRY5R5-1; Fig. 2). The amplified DNA was cloned using a cloning vector pCR-TOPO and sequenced. Sequencing analysis showed that the DNA codes for part of a putative protein that is highly similar $(65 \%$ identical in the corresponding amino acid sequence) to Cry21Aa1, indicating the possibility of the DNA sequence being part of a cry21like gene. This possibility was supported by the successful PCR-amplification and sequencing of cry21-like-gene-related DNAs corresponding to the following degenerate-primer pairs: CRY21F1-1/CRY5R5-1, CRY5F4-1/CRY21R8-3, CRY21F5D2/CRY21R1-1 and CRY21F82/CRY21R3D5 (Table 1 and Fig. 2). Thus, we

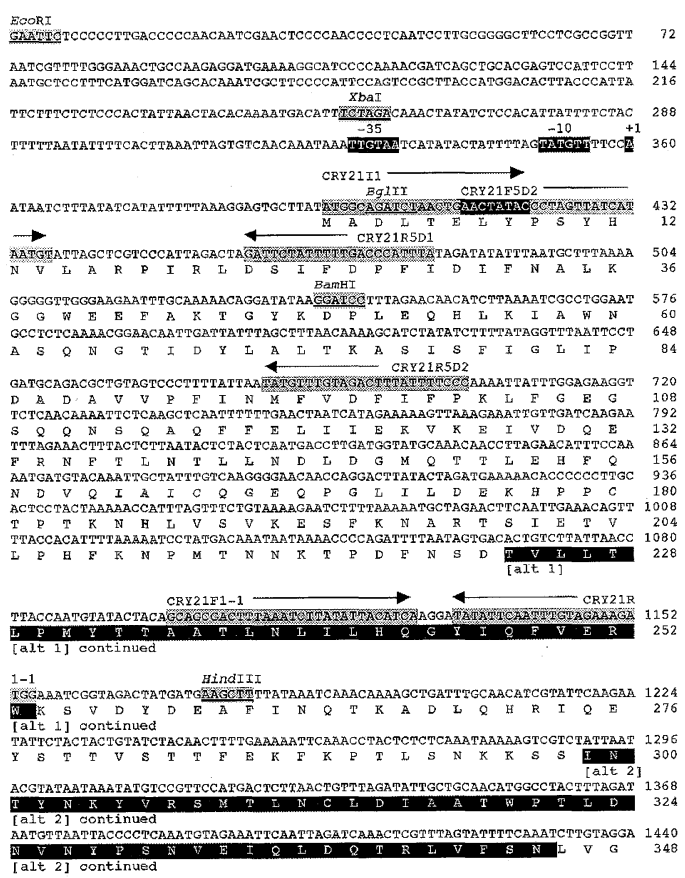

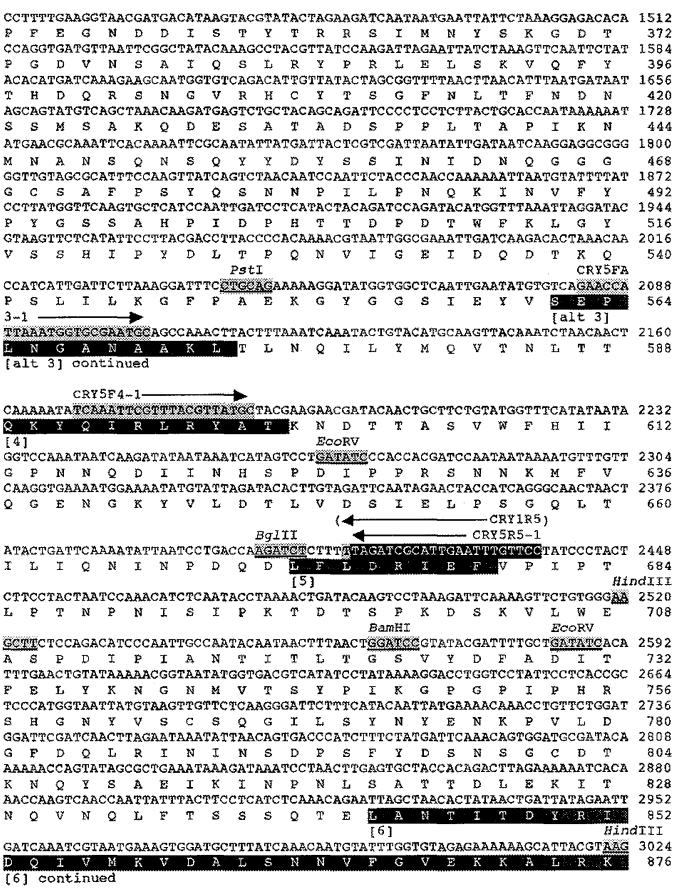

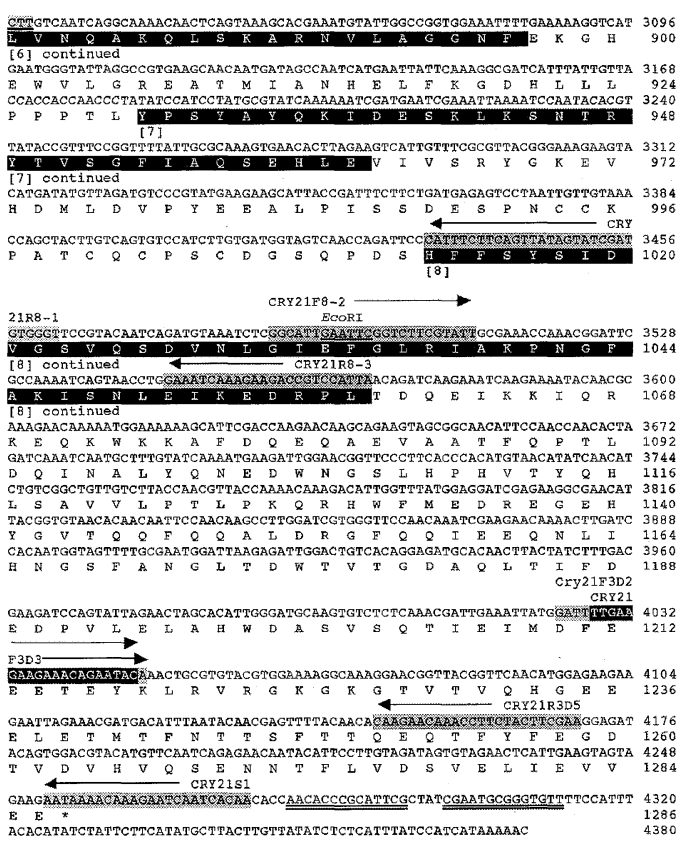

Fig. 1. Nucleotide and the deduced amino-acid sequences of cry21Ba1 from Bacillus thuringiensis serovar roskildiensis. Putative promoter sequences $(-35,-10$ and +1$)$ are indicated as deeply shaded white-letters. Asterisk denotes stop codon. An inverted repeat downstream of the stop codon is indicated as a pair of doubly underlined positions. Major restriction-enzyme sites are underlined and shaded. Priming sites for PCR are neutrally shaded in the nucleotide sequence. Overlaps between two different priming sites are indicated as deeply shaded white-letters. The alternate conserved amino-acid sequence blocks, 1,2 and 3, and the conserved amino-acid sequence blocks, 4, 5, 6,7 and 8, are indicated as [alt 1], [alt 2], [alt 3], [4], [5], [6], [7] and [8], respectively. The conserved blocks are indicated as deeply shaded white-letters in the amino acid sequence. 


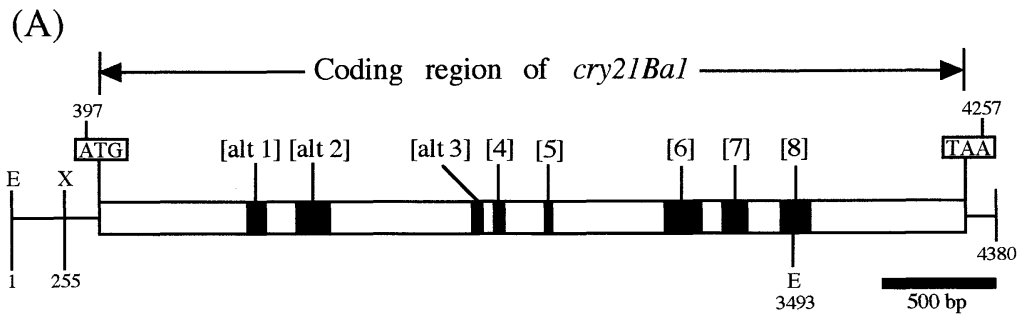

(B)

(2)

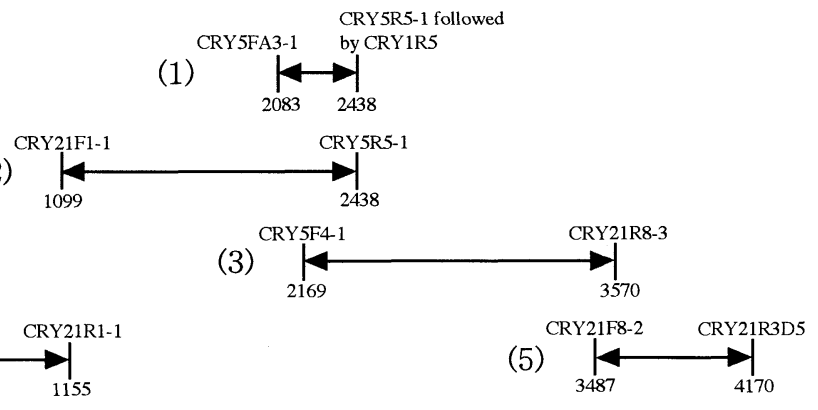

(4)

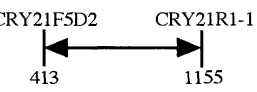

(6)
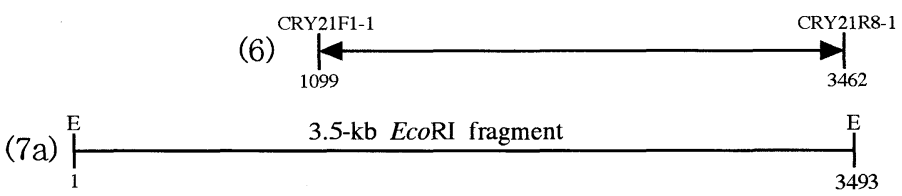

(7b)

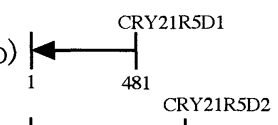

(7c)

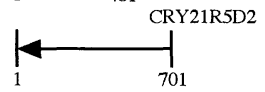

(8a)

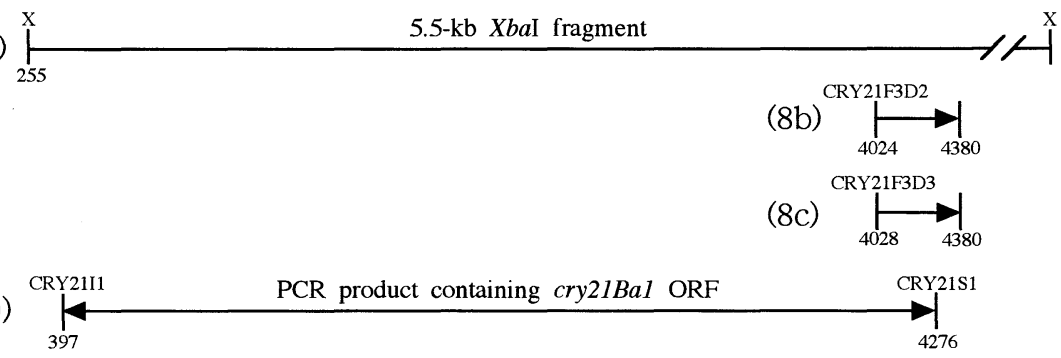

Fig. 2. Sequencing strategy for cry21Ba1 and its flanking regions. (A) The finally sequenced DNA (4,380 bp) is schematically shown. The coding region (positions 397-4257) of cry21Ba1 is indicated by a rectangle. The flanking regions (1-396 and 4258-4380) are indicated by straight lines. Nucleotide sequence coding for each of the eight conserved blocks is indicated as [alt 1], [alt 2], [alt 3], [4], [5], [6], [7] or [8], respectively (see the legend to Fig.1). The nucleotide sequence is indicated by a black box. The length of the nucleotide sequence is drawn to scale. The initiation and stop codons are indicated by boxed letters. The sites for restriction enzymes, $E c o \mathrm{RI}$ and $X b a \mathrm{I}$, are abbreviated as $\mathrm{E}$ and $\mathrm{X}$, respectively. (B) The nucleotide sequence of the positions $413-4170$ of $c r y 21 B a 1$ was clarified by a series of sequencings of PCR products from (1) to (5). PCR products, (5) and (6), were used as probes for the southern hybridization analysis. EcoRI fragment (3.5 kb; 7a) was used as template for the sequencings, i.e., (7b) and (7c), of the 5 ' flanking region. $X b a \mathrm{I}$ fragment ( $5.5 \mathrm{~kb} ; 8 \mathrm{a})$ was used as template for the sequencings, i.e., (8b) and (8c), of the 3 ' flanking region. Amplification of the cry21Ba1 ORF is indicated as (9). An arrow indicates the direction and extent of the amplification reaction. The primer used is indicated on the 5 ' or 3 ' end of the PCR product. The regions each PCR product spans are indicated below the 5 ' and 3 ' ends of the PCR product. 
sequenced a 3,758-bp DNA coding for the positions 413-4170 (the nucleotide sequence lying between two primers, CRY21F5D2 and CRY21R3D5) of the cry21-like gene (i.e., cry21Ba1). This 3,758-bp DNA is lacking in both 5 ' and 3 ' termini of the cry21-like gene.

Southern hybridization analysis:

Southern hybridization analysis was performed in order to identify plasmid DNA(s) carrying the cry21-like gene and restriction-enzyme fragments of the plasmid DNA(s) containing the coding region or the 5 ' or 3 ' flanking region of the gene. The cry21-like gene was detected on 11-kb plasmid DNA(s) (data not shown). The coding region of the gene was detected on several restriction-enzyme fragments of the plasmid DNA(s) including 5.5-kb XbaI fragment(s). The 5 ' and 3' flanking regions of the gene were detected on several restriction-enzyme fragments of the plasmid DNA(s) including $3.5-\mathrm{kb}$ EcoRI fragment(s) and 5.5-kb BglII fragment(s), respectively.

The complete sequence of $c r y 21 B a 1$ :

On the basis of the result of the southern

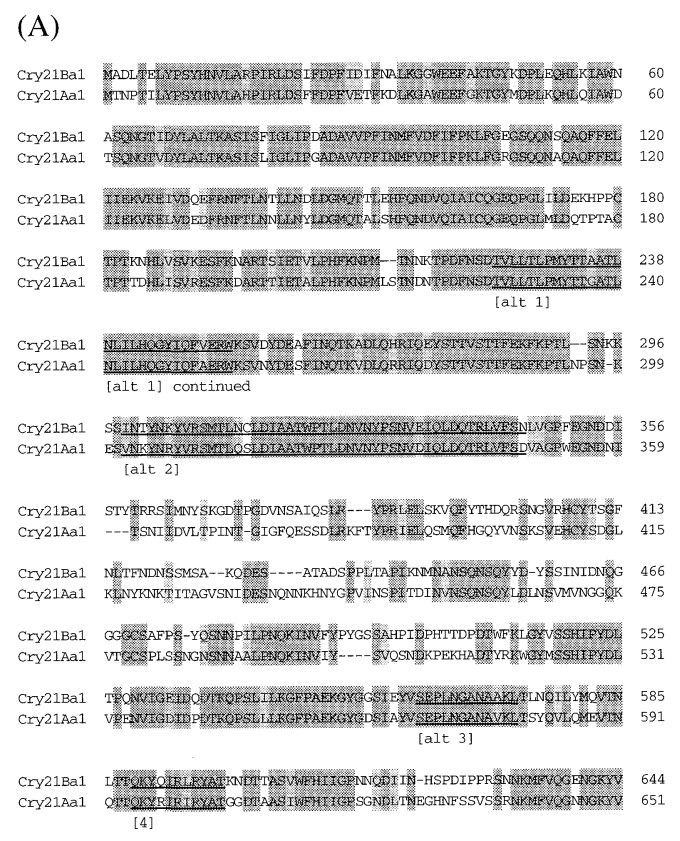

hybridization analysis, the 5' and 3' flanking regions were sequenced as shown in Fig. 2, and finally, a 4,380-bp DNA containing the open reading frame $(\mathrm{ORF})$ of the cry21-like gene was sequenced. The cry21-like-gene ORF is a 3,858bp DNA encoding a Cry21-like protein consisting of 1,286 amino acids. The cry21-like gene now called cry21Ba1 (Crickmore et al., 2004) is shown in Fig. 1.

PCR-amplification of cry21Ba1 ORF:

The cry21Ba1 ORF was successfully PCRamplified with primers (CRY21I1 and CRY21S1) from template (the plasmid DNA fraction or pCR-Blunt vector containing the 5.5-kb XbaI fragment), and the nucleotide sequence of the ORF was confirmed by sequencing (Fig. 2). Therefore, it is possible to express cry $21 \mathrm{Ba} 1$ with recombinant-DNA expression systems such as the acrystalliferous $B$. thuringiensis system (Sasaki et al., 1996) and the $E$. coli system (Wei et al., 2003).

Characterization of cry21Ba1:

The gene, cry21Ba1, has putative promoter sequences upstream of the initiation codon and

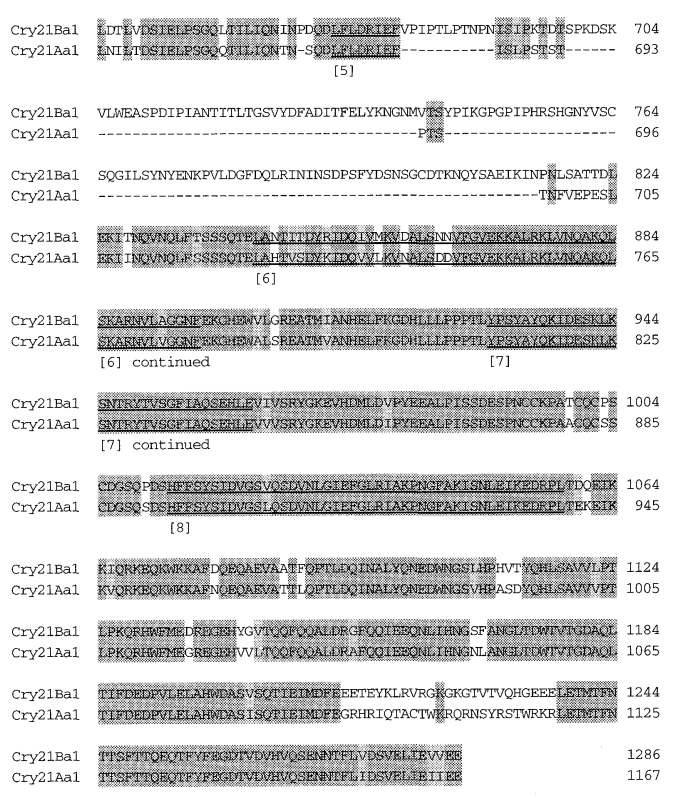


(B)

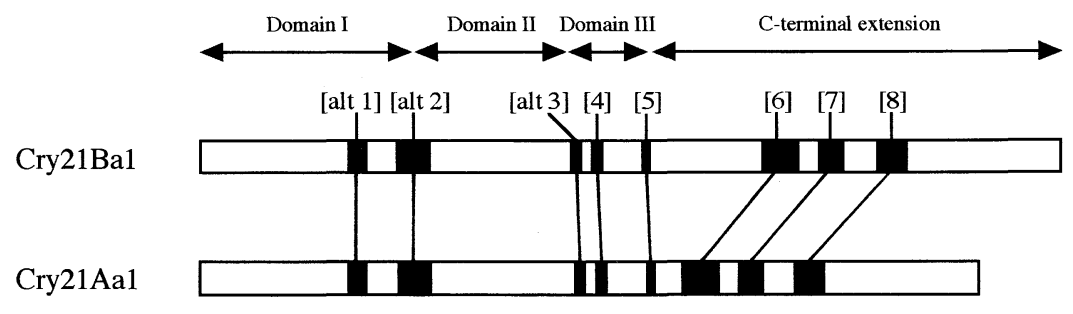

100 amino acids

Fig. 3.(A) Amino-acid sequence alignment of Cry21Ba1 with Cry21Aa1. Identical amino acids are neutrally shaded, and structurally similar amino acids are palely shaded. The conserved blocks, [alt 1], [alt 2], [alt 3], [4], [5], [6], [7] and [8], are defined in the legend to Fig. 1. Each sequence block is underlined in the amino-acid sequence. The amino-acid sequences of Cry21Ba1 and Cry21Aa1 can be cited from the DNA sequence database (DDBJ, NCBI or EMBL) at the accession numbers AB088406 (or BAC06484) and I32932, respectively (for the domain name, see the footnote to Table 1). (B) Comparison of the structures of Cry21Ba1 and Cry21Aa1. Positions of the domains (I, II and III) and the C-terminal extension are each indicated by a double-headed arrow. The conserved blocks, [alt 1], [alt 2], [alt3], [4], [5], [6], [7] and [8], are each indicated by a black box. The length of the amino acid sequence is drawn to scale.

an inverted repeat downstream of the stop codon (Fig. 1), indicating that cry $21 B a 1$ is a functional gene. The nucleotide sequence of the cry $21 \mathrm{Ba1}$ ORF is $75 \%$ identical with that of the cry $21 \mathrm{Aa1}$ ORF. The deduced amino acid sequence of Cry21Ba1 exhibits $67 \%$ identity with the amino acid sequence of Cry21Aa1 (Fig. 3A). High similarity in each sequence of the $\mathrm{N}$-terminal region (the region from the $\mathrm{N}$-terminus to the alternate block 2) and the $\mathrm{C}$-terminal region (the region from the block 6 to the $\mathrm{C}$-terminus) is observed between Cry21Ba1 and Cry21Aa1 (Fig. 3A). On the other hand, the sequences of the internal region (the region from just behind the alternate block 2 to just before the block 6) show relatively low similarity between these Cry proteins (Fig. 3A). Such differences in the amino acid sequences between Cry21Ba1 and Cry21Aa1 suggest that each of these Cry proteins has a distinct nematode-toxicity.

\section{DISCUSSION}

In the present study, we have cloned and sequenced a novel cry gene, $c r y 21 B a 1$, that shows close similarity to cry21Aa1. The gene, cry21Ba1, has been classified into the cry5cry12-cry13-cry14-cry21 group as a new crygene subtype (Crickmore et al., 2004).

According to Schnepf et al. (1998) and de Maagd et al. (2001), it is assumed that the protoxin of Cry21Ba1 consists of three structural domains (domains I, II and III) and a protoxinspecific C-terminal extension (Fig. 3B). The region from the $\mathrm{N}$-terminus to the alternate block 2 corresponds to domain I. The region from the alternate block 2 to just before the alternate block 3 corresponds to domain II. The region from the alternate block 3 to the block 5 corresponds to domain III. The region from just behind the block 5 to the $\mathrm{C}$-terminus corresponds to the $\mathrm{C}$-terminal extension. In reference to the structure-function interaction, it has been suggested that domain I is involved in membrane insertion and pore formation, and domains II and III are both involved in receptor recognition and binding (Schnepf et al., 1998; de 
Maagd et al., 2001). The C-terminal extension is not part of the active Cry toxin. The $\mathrm{C}$-terminal extension of the protoxin of Cry21Bal may be accurately digested by protease(s) in the nematode intestine. Cry21Ba1 differs significantly from Cry21Aa1 in the amino acid sequence of the region comprised of domains II and III (Fig. $3 \mathrm{~A}$ and $\mathrm{B}$ ), indicating the differences between these Cry proteins in the properties of receptor recognition and binding. Therefore, if Cry21Ba1 is nematode-toxic, the toxicity of Cry21Ba1 should differ from that of Cry21Aa1 in the sensitivity spectrum of nematodes and the extent of toxicity.

Is it possible to find $B t$ strains carrying cry genes toxic to plant-pathogenic nematodes? In fact, recently, a new Bt strain, B. thuringiensis serovar jordanica, whose Cry proteins are toxic to root-knot nematodes, Meloidogyne incognita and M. javanica, has been reported (KhyamiHorani et al., 2003). In the near future, $B t$ strains carrying new $c r y$ genes potently toxic to plantpathogenic nematodes may be found.

\section{ACKNOWLEDGMENTS}

We thank the then Professor (now Honorary Professor) T. Iizuka of the Laboratory of Applied Molecular Entomology, Division of Applied Bioscience, Graduate School of Agriculture, Hokkaido University, for his encouragement and support during the course of this study. We also thank Professor K. Suzuki of the Applied Entomology, Department of Agro-Bioscience, Faculty of Agriculture, Iwate University, for his interest in this study.

\section{LITERATURE CITED}

Atkinson, H.J., Urwin, P.E. and McPherson, M.J. (2003) Engineering plants for nematode resistance. Annual Review of Phytopathology 41, 615-639.

Crickmore, N., Zeigler, D.R., Schnepf, E., Van
Rie, J., Lereclus, D., Baum, J, Bravo, A. and Dean, D.H. (2004) Bacillus thuringiensis toxin nomenclature. http://www.biols.susx. ac.uk/Home/Neil_Crickmore/Bt/index.html de Maagd, R.A., Bravo, A. and Crickmore, N. (2001) How Bacillus thuringiensis has evolved specific toxins to colonize the insect world. TRENDS in Genetics 17, 193-199.

Feitelson, J.S. (1997) Identification of, and uses for, nematicidal Bacillus thuringiensis genes, toxins, and isolates. United States patent $5,670,365$.

Griffitts, J.S., Whitacre, J.L., Stevens, D.E. and Aroian, R.V. (2001) Bt toxin resistance from loss of a putative carbohydrate-modifying enzyme. Science 293, 860-864.

Hecker, K.H. and Roux, K.H. (1996) High and low annealing temperatures increase both specificity and yield in touchdown and stepdown PCR. Biotechniques 20, 478-485.

Khyami-Horani, H., Hajaij, M. and Charles, J.-F. (2003) Characterization of Bacillus thuringiensis ser. jordanica (serotype H71), a novel serovariety isolated in Jordan. Current Microbiology 47, 26-31.

Lecadet, M.-M., Frachon, E., Cosmao Dumanoir, V., Ripouteau, H., Hamon, S., Laurent, P. and Thiéry, I. (1999) Updating the H-antigen classification of Bacillus thuringiensis. Journal of Applied Microbiology 86, 660-672.

Lee, L.G., Connell, C.R., Woo, S.L., Cheng, R.D., McArdle, B.F., Fuller, C.W., Halloran, N.D. and Wilson, R.K. (1992) DNA sequencing with dye-labeled terminators and T7 DNA polymerase: effect of dyes and dNTPs on incorporation of dye-terminators and probability analysis of termination fragments. Nucleic Acids Research 20, 2471-2483.

Marroquin, L.D., Elyassnia, D., Griffitts, J.S., Feitelson, J.S. and Aroian, R.V. (2000) Bacillus thuringiensis $(B t)$ toxin susceptibility and isolation of resistance mutants in the 
nematode Caenorhabditis elegans. Genetics 155, 1693-1699.

Narva, K.E., Payne, J.M., Schwab, G.E., Hickle, L.A., Galasan, T. and Sick, A.J. (1991) Novel Bacillus thuringiensis microbes active against nematodes, and genes encoding novel nematode-active toxins cloned from Bacillus thuringiensis isolates. European Patent Office number EP 0462721.

Narva, K.E., Schwab, G.E., Galasan, T. and Payne, J.M. (1993) Gene encoding a nematode-active toxin cloned from a Bacillus thuringiensis isolate. United States patent $5,236,843$.

O'Reilly, D.R., Miller, L.K. and Lukow, V.A. (1992) Baculovirus Expression Vectors. W.H. Freeman and Company, New York, 164pp.

Payne, J.M. and Michaels, T.E. (1995) Bacillus thuringiensis isolates selectively active against certain coleopteran pests. United States patent 5,427,786.

Payne, J.M. and Narva, K.E. (1994) Process for controlling corn rootworm larvae. World Intellectual Property Organization patent WO 94/16079.

Payne, J., Narva, K.E. and Fu, J. (1996) Bacillus thuringiensis genes encoding nematodeactive toxins. United States patent 5,589,382.

Sasaki, J., Asano, S., Iizuka, T., Bando, H., Lay, B.W., Hastowo, S., Powell, G.K. and Yamamoto, T. (1996) Insecticidal activity of the protein encoded by the cry $V$ gene of Bacillus thuringiensis kurstaki INA-02. Current Microbiology 32, 195-200.

Sasser, J.N. and Freckman, D.W. (1987) A world perspective on nematology: the role of the society. In: Vistas on Nematology. (Veech, J.A. and Dickerson, D.W. eds.), Society of Nematologists Inc., Hyattsville, Maryland, 714.

Schnepf, E., Crickmore, N., Van Rie, J., Lereclus, D., Baum, J., Feitelson, J., Zeigler, D.R. and Dean, D.H. (1998) Bacillus thuringiensis and its pesticidal crystal proteins. Microbiology and Molecular Biology Reviews 62, 775-806.

Schnepf, H.E., Schwab, G.E., Payne, J.M., Narva, K.E. and Foncerrada, L. (1992) Novel nematode-active toxins and genes which code therefor. World Intellectual Property Organization patent WO 92/19739.

Sick, A.J., Schwab, G.E. and Payne, J.M. (1994) Genes encoding nematode-active toxins cloned from Bacillus thuringiensis islolates. United States patent 5,281,530.

Wei, J.-Z., Hale, K., Carta, L., Platzer, E., Wong, C., Fang, S.-C. and Aroian, R.V. (2003) Bacillus thuringiensis crystal proteins that target nematodes. Proceedings of The National Academy of Sciences of the United States of America 100, 2760-2765.

Received February 14, 2004. 